\title{
Plasma Wind Tunnel Investigation of European Ablators in Nitrogen/Methane Using Emission Spectroscopy
}

\author{
Ricarda Wernitz, Christoph Eichhorn, Thomas Marynowski, and Georg Herdrich
}

Institute of Space Systems (IRS), University of Stuttgart, Pfaffenwaldring 29, 70569 Stuttgart, Germany

Correspondence should be addressed to Georg Herdrich; herdrich@irs.uni-stuttgart.de

Received 19 March 2013; Revised 16 May 2013; Accepted 21 May 2013

Academic Editor: Jozef Kaiser

Copyright (C) 2013 Ricarda Wernitz et al. This is an open access article distributed under the Creative Commons Attribution License, which permits unrestricted use, distribution, and reproduction in any medium, provided the original work is properly cited.

\begin{abstract}
For atmospheric reentries at high enthalpies ablative heat shield materials are used, such as those for probes entering the atmosphere of Saturn's moon Titan, such as Cassini-Huygens in December, 2004. The characterization of such materials in a nitrogen/methane atmosphere is of interest. A European ablative material, AQ60, has been investigated in plasma wind tunnel tests at the IRS plasma wind tunnel PWK1 using the magnetoplasma dynamic generator RD5 as plasma source in a nitrogen/methane atmosphere. The dimensions of the samples are $45 \mathrm{~mm}$ in length with a diameter of $39 \mathrm{~mm}$. The actual ablator has a thickness of $40 \mathrm{~mm}$. The ablator is mounted on an aluminium substructure. The experiments were conducted at two different heat flux regimes, $1.4 \mathrm{MW} / \mathrm{m}^{2}$ and $0.3 \mathrm{MW} / \mathrm{m}^{2}$. In this paper, results of emission spectroscopy at these plasma conditions in terms of plasma species' temperatures will be presented, including the investigation of the free-stream species, $\mathrm{N}_{2}$ and $\mathrm{N}_{2}{ }^{+}$, and the major erosion product $\mathrm{C}_{2}$, at a wavelength range around $500 \mathrm{~nm}-600 \mathrm{~nm}$.
\end{abstract}

\section{Introduction}

For atmospheric entries concerning celestial bodies such as Saturn's moon Titan, a suitable shielding of the atmospheric entry vehicle from the high heat fluxes generated during such entries is required. For such high speed entries, ablative materials are usually selected as heat shield materials $[1,2]$. Thus, on the one hand, the characteristics of the ablators chosen need to be determined. On the other hand, the processes occurring during ablation are currently not well known and understood. Here, basic investigations into the processes in the boundary layer are required in order to facilitate a better understanding thereof and to enable the choice of and improving a suitable heat shield material. Optical plasma investigation such as emission spectroscopy is well suited to this task, as it enables the identification of the predominant plasma species over the spatial region of interest, providing a great amount of spectral information within the restricted measurement interval of less than $50 \mathrm{~s}$, as well as their temporal progression.

In this paper, therefore, emission spectroscopic results of four representative measurements at two heat flux regimes and two measurement distances to the probe surface each will be presented. These measurements are both resolved in time and space in the vertical direction perpendicular to the plasma jet axis. Results are presented in terms of plasma species vibration and rotation temperatures obtained fitting a numerically obtained spectrum to the measured one. A temporal as well as a spatial profile of these temperatures is presented for each test case.

An investigation into surface recession or in-depth specimen temperatures is not included in this paper.

\section{Test Facility, Probe Geometry, and Plasma Conditions}

Four experiments in all were conducted in the IRS plasma wind tunnel facility PWK1 using the magneto-plasma dynamic generator RD5 $[3,4]$. The vacuum tank used for PWK 1 is a $6 \mathrm{~m}$ long steel tank with a diameter of $2 \mathrm{~m}$ and a double-wall cooling. It is closed with a hemispherical part which is connected to the vacuum system and protected against heat by water-cooled copper shields. On the other side the vacuum chamber can be opened by moving a plane cover plate on a guide rail. The plasma source is not located 


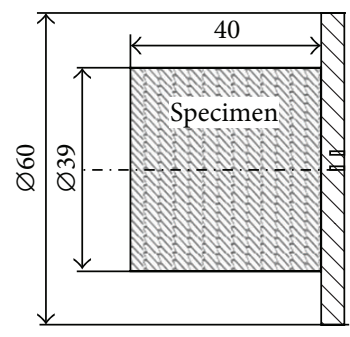

(a)

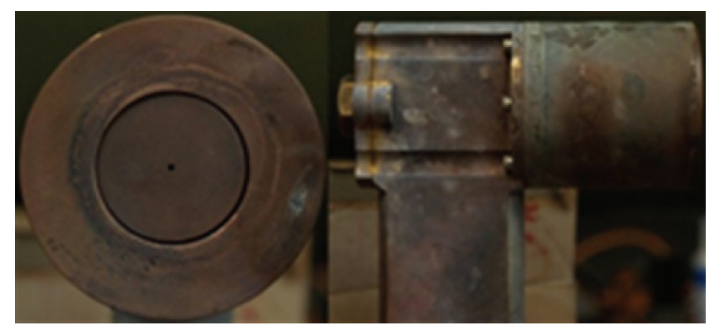

(b)

FIgURE 1: Sample geometry (a) and combined $80 \mathrm{~mm}$ heat flux and Pitot pressure probe (b).

in the vacuum tank but flanged on a conical part of the plate. The cone-shaped element of the end plate enables the plasma source to be fixed at that point. The whole plasma jet range is accessible by optical methods. The facility is equipped with a 4 -axis positioning system on which the different probes and the specimen support system can be mounted. This allows the simulation of parts of the reentry trajectories by automatically moving the specimen in different plasma flow regimes. A certain point on a reentry trajectory is defined by the ambient pressure, the axial distance to the generator, the arc current, and the mass flow. Together, these values result in adequate enthalpy, total pressure, and temperature or heat flux. Optical glass windows allow pyrometric temperature measurements on the front side of the specimen at distances from the plasma source between about $50 \mathrm{~mm}$ and $1 \mathrm{~m}$. Moreover, optical measurements perpendicular to the plasma jet axis are possible through three movable flanges of three optical glasses each, which are located on both sides of the tank opposite to each other and on the top. The electric power is supplied by a current-regulated thyristor rectifier consisting of six identical units supplying $1 \mathrm{MW}$ each. These may be connected in series or parallel, thus varying the desired output level of current, voltage, and power. The current ripple is less than $0.5 \%$. The maximum current is $48 \mathrm{kA}$ supplied at $125 \mathrm{~V}$, and the maximum voltage is $6 \mathrm{kV}$ at a current of $1 \mathrm{kA}$. Self-field MPGs of different sizes have been developed over the past decades at IRS; they are employed successfully in the IRS plasma wind tunnels PWK 1 and PWK 2. The nozzle-type MPG plasma generators consist of two coaxial electrodes, separated by water-cooled neutrodes. The nozzle exit, which is also a water-cooled segment, forms the anode. The cathode, made of $2 \%$ thoriated tungsten, is mounted in the center of the plenum chamber. The arc is ignited by a Paschen breakdown. The current passes through the expansion nozzle from the cathode tip to the end of the nozzle. The test gas is dissociated and partly ionized. To avoid oxidation of the cathode, only the nitrogen component of the test gas is fed in along the cathode into the plenum chamber, heated up by the arc, and accelerated partly by thermal expansion and partly by electromagnetic forces due to the self-induced magnetic field in the nozzle. The magnitude of the magnetic acceleration force strongly depends on the current level of operation. With this MPG, the oxygen needed for the duplication of high enthalpy air flows is fed in radially at a high velocity at the supersonic part of the nozzle but still within the arc region.
The various gas injection points enable the operation of the MPG with different gas mixtures. So the investigation of entry maneuvers into the atmospheres of other celestial bodies such as Titan and Mars, containing $\mathrm{CH}_{4}$ and $\mathrm{CO}_{2}$, is possible [3].

Special efforts have been made to minimize the erosion of the plasma generator. To avoid a spotty arc attachment on the anode, which would cause a contamination of the plasma flow, a small amount of argon is injected tangentially along the anode contour. This method has been shown experimentally to eliminate anode erosion. Within the whole region of operation the only contaminating part of the MPG is the cathode. The $2 \%$ thoriated tungsten cathode reaches more than $3000 \mathrm{~K}$ during steady-state operation. The high temperature and the low work function of the cathode result in a diffuse arc attachment and, consequently, a very low cathode erosion rate at the order of sublimation. The very low cathode erosion results in operation periods of the MPG of hundreds of hours.

For the MPG generator RD5 with a nozzle exit diameter of $125 \mathrm{~mm}$, the mass flows for air are between $0.3 \mathrm{~g} / \mathrm{s}$ and $50 \mathrm{~g} / \mathrm{s}$ at current levels between $200 \mathrm{~A}$ to $4 \mathrm{kA}$ and power levels of $40 \mathrm{~kW}$ to $1 \mathrm{MW}$, while the average specific enthalpy at the nozzle exit varies between $2 \mathrm{MJ} / \mathrm{kg}$ and $150 \mathrm{MJ} / \mathrm{kg}$.

For testing large TPS structures an MPG generator with an enlarged nozzle was built. The nozzle diameter of RD7 is $320 \mathrm{~mm}$, which enables the investigation of TPS materials and substructures up to $400 \mathrm{~mm}$ in diameter [3].

For the experimental entry simulations for Titan, a gas mixture of $98.5 \% \mathrm{~N}_{2}$ and $1.5 \% \mathrm{CH}_{4}$ was chosen. Here, two test conditions have been chosen, at heat fluxes of $1.4 \mathrm{MW} / \mathrm{m}^{2}$, at a testing time of $25 \mathrm{~s}$, and of $0.3 \mathrm{MW} / \mathrm{m}^{2}$, at a testing time of $50 \mathrm{~s}$; see Table 1 . For each test condition two tests have been performed using the common European ablative material AQ60. This material is a standard ablation-based heat shield material for atmospheric entry capsules entering atmospheres under modest heat loads. It was, for example, used as heat shield material for the European Huygens Titan entry probe and is an isotropic material made of $10 \%$ (volume) glass fiber and $6 \%$ phenolic resin. The material has a very low density $\left(0.3 \mathrm{~g} / \mathrm{cm}^{3}\right)$ and very good insulation properties; see also [3]. The dimensions of the samples are approximately $45 \pm 0.2 \mathrm{~mm}$ in length with a diameter of the ablative material of $39 \pm 0.2 \mathrm{~mm}$. The actual ablator has a thickness of $40 \pm 0.2 \mathrm{~mm}$. The ablator is mounted on an 
TABLE 1: Plasma test conditions $\mathrm{C} 1$ and $\mathrm{C} 2$.

(a)

\begin{tabular}{lc}
\hline Overall facility conditions & \\
\hline Current & $1006.7 \pm 2.3[\mathrm{~A}]$ \\
Methane mass flow & $87.15 \pm 0.07[\mathrm{mg} / \mathrm{s}]$ \\
Nitrogen mass flow & $10.036 \pm 0.008[\mathrm{~g} / \mathrm{s}]$ \\
Argon mass flow & $1.47 \pm 0.002[\mathrm{~g} / \mathrm{s}]$ \\
Total mass flow & $10.123 \pm 0.008[\mathrm{~g} / \mathrm{s}]$ \\
Ambient pressure & $15.96 \pm 0.04[\mathrm{hPa}]$ \\
\hline
\end{tabular}

(b)

\begin{tabular}{lc}
\hline Condition C1 & \\
\hline$x$-position & $255 \pm 0.001[\mathrm{~mm}]$ \\
Heat flux & $1.4208 \pm 0.0031\left[\mathrm{MW} / \mathrm{m}^{2}\right]$ \\
Pitot pressure & $17.75 \pm 0.02[\mathrm{hPa}]$ \\
\hline
\end{tabular}

(c)

\begin{tabular}{lc}
\hline Condition C2 & \\
\hline$x$-position & $510 \pm 0.001[\mathrm{~mm}]$ \\
Heat flux & $0.3103 \pm 0.0028\left[\mathrm{MW} / \mathrm{m}^{2}\right]$ \\
Pitot pressure & $16.78 \pm 0.02[\mathrm{hPa}]$ \\
\hline
\end{tabular}

(d)

\begin{tabular}{lccc}
\hline $\begin{array}{l}\text { Test } \\
\text { condition }\end{array}$ & $\begin{array}{c}\text { Heat flux/ } \\
\mathrm{MW} / \mathrm{m}^{2}\end{array}$ & $\begin{array}{c}\text { Total pressure/ } \\
\mathrm{hPa}\end{array}$ & Testing time/s \\
\hline $\mathrm{C} 1$ & 1.42 & 17.8 & 25 \\
$\mathrm{C} 2$ & 0.31 & 16.8 & 50 \\
\hline
\end{tabular}

(e)

\begin{tabular}{lcc}
\hline Test condition & $\begin{array}{c}\text { Free-stream Mach } \\
\text { number/- }\end{array}$ & $\begin{array}{c}\text { Maximum sample surface } \\
\text { temperature } /{ }^{\circ} \mathrm{C}\end{array}$ \\
\hline $\mathrm{C} 1$ & $0.36-0.44$ & 1873,1834 \\
$\mathrm{C} 2$ & $0.25-0.30$ & 1164,1145 \\
\hline
\end{tabular}

aluminium substructure and installed into a water-cooled copper probe with a diameter of $80 \mathrm{~mm}$; see Figure 1.

Figure 1, however, depicts the constellation of the sample holder with the steady state calorimetric heat flux sensor inserted. This sensor has the same diameter as the ablation samples and allows the determination of copper-based heat fluxes including the simultaneous measurement of the Pitot pressure (see the bore in the center of the front view of the plasma probe system). Heat fluxes and total pressures were correspondingly measured in previously performed calibration tests using the combined Pitot pressure and copper heat flux probe setup with a diameter of $80 \mathrm{~mm}$ and the insert for heat flux determination of $40 \mathrm{~mm}$ diameter.

Table 1 shows the facility conditions and, in addition, the individual parameters of conditions $\mathrm{C} 1$ and $\mathrm{C} 2$.

Surface temperatures given in Table 1 (bottom) were obtained using the linear pyrometer LP3 at an operating wavelength of $726.5 \mathrm{~nm}$, which covers a temperature range

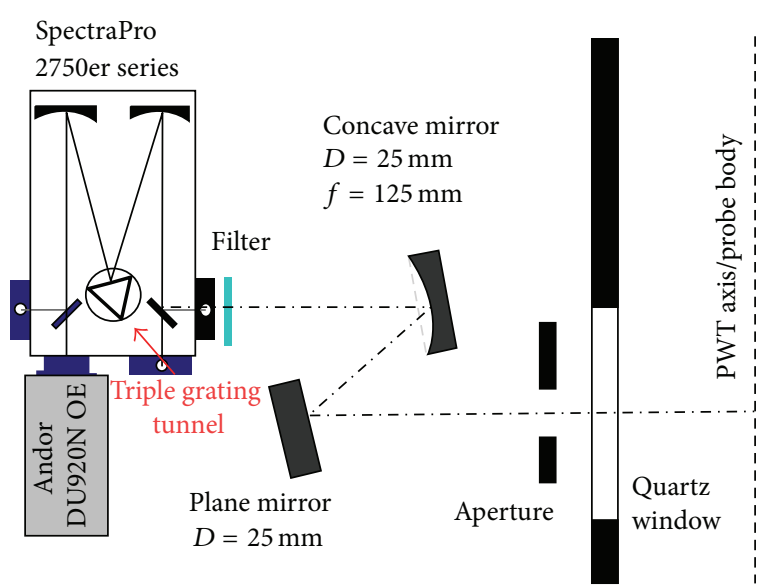

Figure 2: Experimental setup for emission spectroscopy, including camera, spectrograph, and optical setup.

up to $3000^{\circ} \mathrm{C}$ and even higher. This pyrometer is manufactured by KE, Germany.

Mach numbers have been estimated according to Herdrich and Petkow [5] using adiabatic coefficients of $1.1<\gamma<$ 1.67:

$$
\mathrm{Ma}=\sqrt{\frac{2}{\gamma-1}\left[\left(\frac{p_{\mathrm{tot}}}{p_{\mathrm{amb}}}\right)^{(\gamma-1 / \gamma)}-1\right] .}
$$

This formula is valid for the subsonic case, only. However, as shown in Table 1, the plasma condition is clearly subsonic and the boundary layer is artificially broadened by the flat face probe design, enabling measurements at the axial distances of $3 \mathrm{~mm}$ and $5 \mathrm{~mm}$ investigated here.

Local specific enthalpies are generally estimated using Marvin and Pope's [6] method, employing an effective probe nose radius as determined by Boisen and Curtiss [7] of 2.7 times the probe radius. However, for a methane/nitrogen atmosphere, the factor $K$ employed by Pope is not known; hence no enthalpy calculation for the plasma conditions investigated here could be performed.

\section{Experimental Setup for Emission Spectroscopy}

The experimental setup for the emission spectroscopic investigation of the plasma jet and ablative measurements is displayed in Figure 2. A monochromator/spectrograph in Czerny-Turner configuration, ACTON SpectraPro 2750 (by Princeton Instruments), with a focal length of $f=750 \mathrm{~mm}$, an aperture ratio of $f / d=9.7$, and both $300 \mathrm{~L} / \mathrm{mm}$ and $600 \mathrm{~L} / \mathrm{mm}$ gratings are used. A micrometer controlled side entrance slit is included in the spectrometer. For data acquisition, a CCD camera (ANDOR Newton DU920N-OE) is used. Measurements are conducted in imaging mode. Thus, spectra are composed of 255 separate spectra recorded for each row of the CCD and provide additional information on the vertical spatial distribution of the plasma (radial intensity profile of the plasma jet) and the ablative process. 
TABLE 2: Parameters of spectroscopic setup.

\begin{tabular}{lcccc}
\hline $\begin{array}{l}\text { Test } \\
\text { cond. }\end{array}$ & $\begin{array}{c}\text { Spectrometer } \\
\text { grid }\end{array}$ & $\begin{array}{c}\text { Exposure } \\
\text { time/frame } \\
\text { rate }\end{array}$ & $\begin{array}{c}\text { Wavelength } \\
\text { range/nm }\end{array}$ & $\begin{array}{c}\text { Distance to } \\
\text { probe surface }\end{array}$ \\
\hline $\mathrm{C} 1$ & $600 \mathrm{~L} / \mathrm{mm}$ & $1 \mathrm{~s} / 1.1874 \mathrm{~s}$ & $525-575$ & $5 \mathrm{~mm}$ \\
$\mathrm{C} 1$ & $300 \mathrm{~L} / \mathrm{mm}$ & $1 \mathrm{~s} / 1.1874 \mathrm{~s}$ & $500-600$ & $3 \mathrm{~mm}$ \\
$\mathrm{C} 2$ & $600 \mathrm{~L} / \mathrm{mm}$ & $1 \mathrm{~s} / 1.1874 \mathrm{~s}$ & $525-575$ & $5 \mathrm{~mm}$ \\
$\mathrm{C} 2$ & $600 \mathrm{~L} / \mathrm{mm}$ & $1 \mathrm{~s} / 1.1874 \mathrm{~s}$ & $525-575$ & $3 \mathrm{~mm}$ \\
\hline
\end{tabular}

Light emitted from an area $5 \pm 1 \mathrm{~mm}$ or $3 \pm 1 \mathrm{~mm}$ in front of the probe surface is focused onto the spectrometer entrance slit via two mirrors, a plane mirror reflecting the emission of the plasma jet onto a concave mirror with a focal length of $f=125 \mathrm{~mm}$ and a ratio of $f / d=6.25$. For plasma characterization at wavelengths above $450 \mathrm{~nm}$, a suitable filter is included in the setup to avoid influence of second-order spectra, directly in front of the spectrometer entrance slit. Additionally, an aperture has been installed in front of the optical setup, reducing the intensity and the influence of aberrations.

Test parameters including spectrometer grids, $300 \mathrm{~L} / \mathrm{mm}$ and $600 \mathrm{~L} / \mathrm{mm}$, exposure times $(1 \mathrm{~s}$ at a measurement frequency of $1.1874 \mathrm{~Hz}$ ), and wavelength ranges are given in Table 2. A wavelength range between approximately 525$575 \mathrm{~nm}$ has been chosen, as in this range, $\mathrm{C}_{2}$, a wellknown product in ablation processes using carbon containing ablators, is a strong radiator.

Spectra were taken $5 \pm 1 \mathrm{~mm}$ and $3 \pm 1 \mathrm{~mm}$ in front of the probe surface. Here, by placing a light source with a $0.2 \mathrm{~mm}$ aperture in the measurement region and moving it in $0.2 \mathrm{~mm}$ increments in the axial direction, one obtains an axial intensity distribution. Fitting a Gaussian to these intensities yields an area of $1.5 \mathrm{~mm}$ (axial) width at half maximum, which the radiation incident on the spectrometer originates from.

In the vertical direction, $51 \mathrm{~mm}$ of the plasma jet core has been observed and is distributed over 255 pixel lines, yielding a maximum possible vertical resolution of $0.2 \mathrm{~mm} /$ pixel. Effectively, vertical resolution is $0.6 \mathrm{~mm}$ at half maximum. This vertical resolution was obtained by placing a light source with a $0.2 \mathrm{~mm}$ aperture in front of the optical setup and determining the width at half maximum of the resulting peak on the camera's CCD.

Summarizing, all spectra are an integration of an area of $1.5 \times 0.6 \mathrm{~mm}^{2}$ at half maximum, taken $3 \pm 1 \mathrm{~mm}$ and $5 \pm 1 \mathrm{~mm}$ in front of the sample.

Spectra were obtained using $300 \mathrm{~L} / \mathrm{mm}$ and $600 \mathrm{~L} / \mathrm{mm}$ grids at a maximum theoretical spectral resolution of $0.12 \mathrm{~nm} /$ pixel and $0.06 \mathrm{~nm} /$ pixel, respectively. The wavelength calibration has been conducted comparing lines of a conventional mercury lamp to pixel numbers and using a 3rd degree polynomial fit. Intensity calibration was conducted using an integrating sphere (Ulbricht sphere). It consists of a hollow spherical cavity with its interior covered with a diffuse white reflective coating, with small holes for entrance and exit port(s). Therefore, it provides a uniform diffusing effect. Light rays incident on any point on the inner surface are distributed equally to all other points. Hence, effects of the original direction of the light are minimized. An integrating sphere may be thought of as a radiation diffuser which preserves power but destroys spatial information. It is typically used with some light source and a detector for optical power measurement. Correspondingly, measurements of power flux can be performed without inaccuracy caused by the directional characteristics of the source. Therefore, the sphere creates a reference radiation source.

\section{Emission Spectroscopic Free-Stream Characterization}

Before analyzing ablation species and processes, the freestream needs to be characterized for both plasma conditions at $1.4 \mathrm{MW} / \mathrm{m}^{2}$ and $0.3 \mathrm{MW} / \mathrm{m}^{2}$.

For the nitrogen/methane gas composition used, $\mathrm{CN}, \mathrm{N}_{2}$, and $\mathrm{N}_{2}{ }^{+}$have been identified as the predominant plasma species, $\mathrm{CN}$, resulting from the methane fraction of the gas mixture.

In Figures 3 and 4 two observed spectra are shown. In addition, emission spectra have been simulated using the PARADE [8] (plasma radiation database) program. PARADE is the plasma radiation database that was developed by Fluid Gravity Engineering and the Institute of Space Systems (IRS) for ESA. The currently available version can be obtained upon request from ESTEC (within member state entities). The code can be either used independently (as in this work) or in a coupled mode that is coupled to an adequate CFD code. A Monte Carlo-based radiation transport code is used for coupling (HERTA). Examples are simulated spectra for entry capsules such as STARDUST [9] or the simulation of test cases within ESA's radiation working group [10].

Rotational and vibrational temperatures at the plasma jet center have been extracted, computing the optimal fit of a simulated spectrum to a measured one. Since, for the investigation of the free-stream temperatures at $3 \mathrm{~mm}$ and $5 \mathrm{~mm}$ distance to the probe surface the difference in the plasma composition is very small, results for those two distances for the free-stream are not presented separately.

All spectra have been normalized with their respective maxima in order to facilitate comparability between the molecular bands of the simulated and measured spectra.

In Figure 3, for heat fluxes of $1.4 \mathrm{MW} / \mathrm{m}^{2}, \mathrm{~N}_{2}, \mathrm{~N}_{2}{ }^{+}$, and $\mathrm{CN}$ have been identified as the predominant emitters. At the plasma jet center (plasma jet axis), CN shows vibrational temperatures of approximately $T_{\mathrm{vib}}=8000 \mathrm{~K}$, and rotational temperatures of $T_{\text {rot }}=9000 \mathrm{~K}$. Temperatures for $\mathrm{N}_{2}$ range from $T_{\text {vib }}=3000 \mathrm{~K}$ and $T_{\text {rot }}=5000 \mathrm{~K}$ and for $\mathrm{N}_{2}{ }^{+}$from $T_{\text {vib }}=10000 \mathrm{~K}$ and $T_{\text {rot }}=11000 \mathrm{~K}$.

In Figure 4 for heat fluxes of $0.3 \mathrm{MW} / \mathrm{m}^{2} \mathrm{~N}_{2}{ }^{+}$and $\mathrm{CN}$ are the predominant species; see Figure 4. For plasma condition $\mathrm{C}_{2}$ no $\mathrm{N}_{2}$ emission was detected, which may however be due to the emission of $\mathrm{N}_{2}$ being very weak in comparison to $\mathrm{N}_{2}{ }^{+}$and $\mathrm{CN}$, which are strong radiators at the wavelength range $(290 \mathrm{~nm}-410 \mathrm{~nm})$ investigated for the free-stream. At the plasma jet center, $\mathrm{CN}$ shows vibrational temperatures of $T_{\text {vib }}=6000 \mathrm{~K}$ and rotational temperatures of $T_{\text {rot }}=8000 \mathrm{~K}$. 


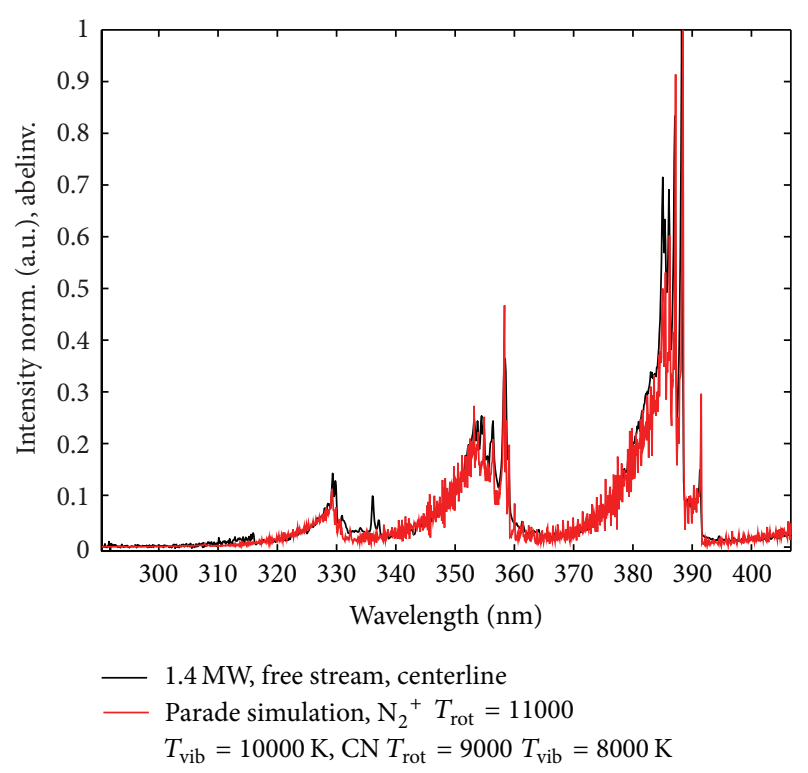

Figure 3: Measured (black) and simulated (red) free-stream spectra at the plasma jet center for plasma condition $\mathrm{Cl}$, including the simulated plasma species $\mathrm{N}_{2}\left(T_{\text {rot }}=5000 \mathrm{~K}, T_{\text {vib }}=3000 \mathrm{~K}\right), \mathrm{N}_{2}{ }^{+}$ $\left(T_{\text {rot }}=11000 \mathrm{~K}, T_{\text {vib }}=10000 \mathrm{~K}\right)$, and $\mathrm{CN}\left(T_{\text {rot }}=9000 \mathrm{~K}, T_{\text {vib }}=\right.$ $8000 \mathrm{~K})$.

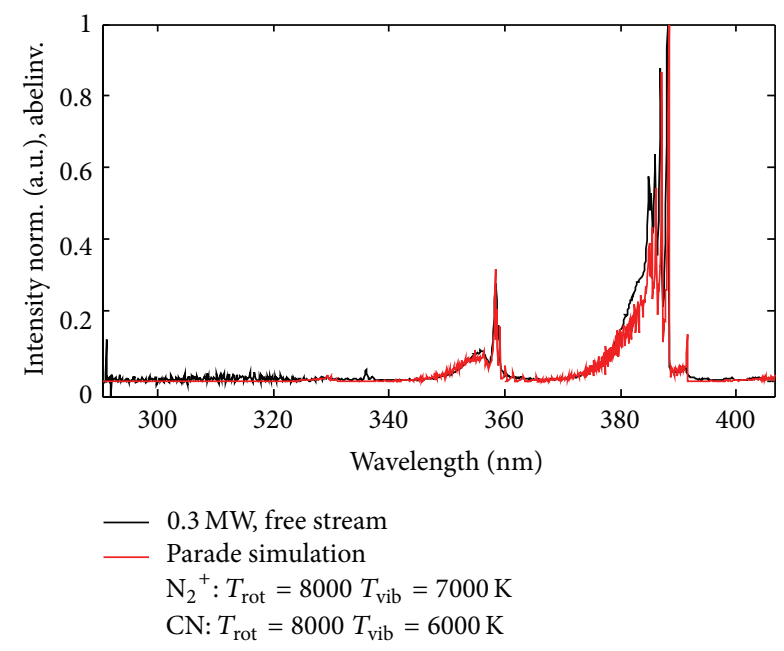

FIGURE 4: Measured (black) and simulated (red) free-stream spectra at plasma jet center for plasma condition $\mathrm{Cl}$, including the simulated plasma species $\mathrm{N}_{2}{ }^{+}\left(T_{\text {rot }}=8000 \mathrm{~K}, T_{\text {vib }}=7000 \mathrm{~K}\right)$ and $\mathrm{CN}\left(T_{\text {rot }}=\right.$ $\left.8000 \mathrm{~K}, T_{\mathrm{vib}}=6000 \mathrm{~K}\right)$.

Temperatures for $\mathrm{N}_{2}{ }^{+}$range from $T_{\text {vib }}=7000 \mathrm{~K}$ and $T_{\text {rot }}=$ $8000 \mathrm{~K}$.

\section{Emission Spectroscopic Results for $1.4 \mathrm{MW} / \mathrm{m}^{2}$}

For the study of ablation, experiments concentrated on the emission of a common ablative plasma species, $\mathrm{C}_{2}$. Here, the wavelength range chosen for all detected spectra facilitates the observation of a Swan band of $\mathrm{C}_{2}, 1,2$ and 0,1 .
TABLE 3: Rotational and vibrational temperatures obtained using PARADE for $\mathrm{C}_{2}$ at $1.4 \mathrm{MW} / \mathrm{m}^{2}$ at $3 \mathrm{~mm}$ and $5 \mathrm{~mm}$ axial distance to probe surface.

\begin{tabular}{lcc}
\hline $\begin{array}{l}\text { Distance to probe } \\
\text { surface }\end{array}$ & $\begin{array}{c}\mathrm{C}_{2} \text { rotational } \\
\text { temperatures } / \mathrm{K}\end{array}$ & $\begin{array}{c}\mathrm{C}_{2} \text { vibrational } \\
\text { temperatures/K }\end{array}$ \\
\hline $3 \mathrm{~mm}$ & $5000-6500$ & $6000-7000$ \\
$5 \mathrm{~mm}$ & $5000-6500$ & $5000-6500$ \\
\hline
\end{tabular}

Swan bands were originally a characteristic of the spectra of carbon stars, comets, and of burning hydrocarbon fuels. They are named after the Scottish physicist William Swan who first studied the spectral analysis of radical carbon $\mathrm{C}_{2}$ in 1856 .

The wavelength range allows for the observation of $\mathrm{C}_{2}$ without disturbing influence of other plasma species. Particularly CN was to be avoided, as it is a strong radiator and ablation product, but also, here, present in the freestream.

For plasma condition $\mathrm{Cl}$, emission spectra of $\mathrm{C}_{2}$ were taken using a $600 \mathrm{~L} / \mathrm{mm}$ grid at a wavelength range of $525 \mathrm{~nm}-575 \mathrm{~nm}$ at a distance of $5 \pm 1 \mathrm{~mm}$ to the probe surface. A second test has been performed at a distance of $3 \pm 1 \mathrm{~mm}$ to the probe surface using a $300 \mathrm{~L} / \mathrm{mm}$ grid at a wavelength range of approximately $500 \mathrm{~nm}-600 \mathrm{~nm}$. Plasma species temperatures were obtained by fitting simulated spectra to measured ones, while changing rotational and vibrational temperatures of the predominant species $(\mathrm{CN}$ and $\mathrm{N}_{2}{ }^{+}$) and adjusting the density quotient of $\mathrm{N}_{2} / \mathrm{N}_{2}{ }^{+} / \mathrm{C}_{2}$. The temperature of $\mathrm{N}_{2}$ does not show any significant influence on the spectra; thus they were set to the equilibrium temperatures $T_{\text {rot }, \mathrm{N}_{2}}=T_{\text {vib, } \mathrm{N}_{2}}=5000 \mathrm{~K}$. Table 3 shows an overview outcome for the $\mathrm{C}_{2}$ temperatures for $1.4 \mathrm{MW} / \mathrm{m}^{2}$ heat flux at the distanc $3 \mathrm{~mm}$ and $5 \mathrm{~mm}$.

5.1. $5 \mathrm{~mm}$ Axial Distance to Probe Surface. At a heat flux of $1.4 \mathrm{MW} / \mathrm{m}^{2}$, the investigation of $\mathrm{N}_{2}{ }^{+}$during ablation yielded constant temperatures of $T_{\text {rot }}=9000 \mathrm{~K}$ and $T_{\text {vib }}=10000 \mathrm{~K}$ perpendicular to the plasma jet axis along the probe surface.

Although considerably weaker compared to the emission band of $\mathrm{CN}$, parts of the $\mathrm{C}_{2}$ Swan band could be well observed during the first second. Figure 5 exemplary shows one observed spectrum and its respective optimum PARADE fit.

Leaving the density quotient of $\mathrm{N}_{2} / \mathrm{N}_{2}{ }^{+} / \mathrm{C}_{2}=3000 / 70 / 1$ constant, temperatures of $\mathrm{C}_{2}$ increase with perpendicular distance to the probe center from $T_{\text {rot }}=5000 \mathrm{~K}$ and $T_{\text {vib }}=$ $5000 \mathrm{~K}$ at the probe center to $T_{\text {rot }}=6000 \mathrm{~K}$ and $T_{\text {vib }}=6500 \mathrm{~K}$ at a distance of $32.4 \mathrm{~mm}$ to the probe center. However, it is interesting to note that simulated and measured spectra are also in acceptable agreement if the density of $\mathrm{C}_{2}$ is halved at that distance.

Additional to the spatial distribution of $\mathrm{C}_{2}$ emission along the probe surface, $\mathrm{C}_{2}$ temperatures and concentrations (in terms of emission intensity) show a temporal progression. $\mathrm{C}_{2}$ emission intensity decreases with time. After approximately $5 \mathrm{~s}$ of exposure of the probe to the plasma, $\mathrm{C}_{2}$ intensity in the molecular band observed in this study is almost nonexistent. 


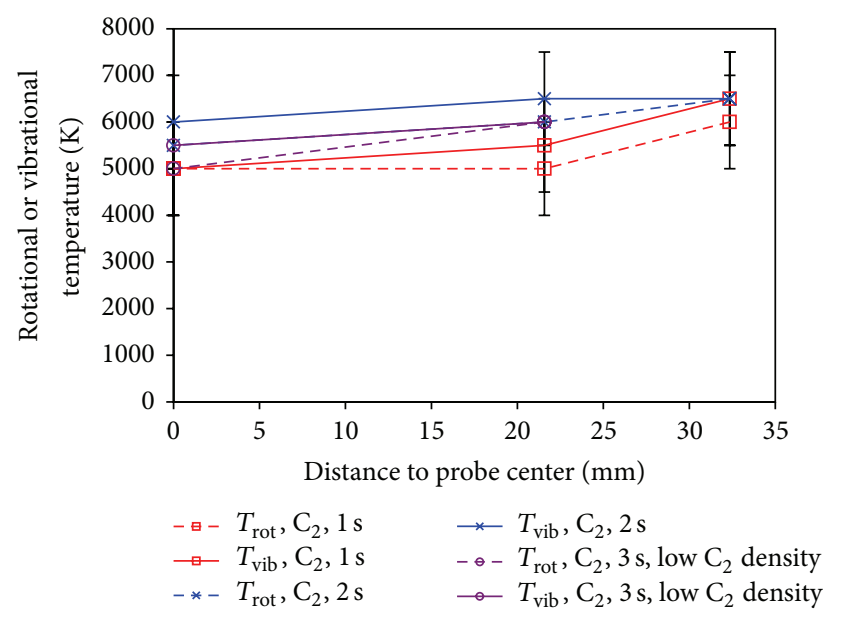

(a)

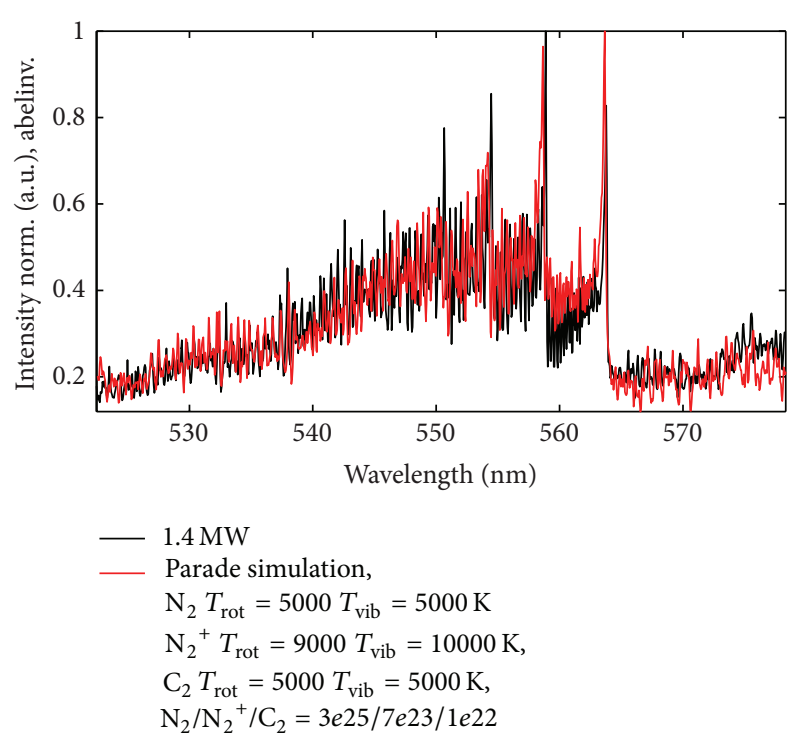

(b)

Figure 5: (a) Temporal evolution of measured spectra of $\mathrm{C}_{2}$ at $1.4 \mathrm{MW} / \mathrm{m}^{2} 3 \mathrm{~mm}$ in front of probe surface. (b) Measured (black) and simulated (red) spectra at $21.5 \mathrm{~mm}$ distance to probe center for plasma condition $\mathrm{Cl}$, including the simulated plasma species $\mathrm{N}_{2}^{+}\left(T_{\text {rot }}=9000 \mathrm{~K}\right.$, $\left.T_{\text {vib }}=10000 \mathrm{~K}\right)$ and $\mathrm{CN}\left(T_{\text {rot }}=5000 \mathrm{~K}, T_{\text {vib }}=6000 \mathrm{~K}\right)$.

Reliable simulations could therefore only be obtained until $3 \mathrm{~s}$ into ablation. Here, $\mathrm{C}_{2}$ emission at $32.4 \mathrm{~mm}$ vertical distance to the probe symmetry axis was too weak to yield reasonable simulation results.

Summarizing, at plasma condition $\mathrm{C} 1$ at $5 \mathrm{~mm}$ axial distance to the probe surface, $\mathrm{N}_{2}{ }^{+}$showed constant temperatures of $T_{\text {rot }}=9000 \mathrm{~K}$ and $T_{\text {vib }}=10000 \mathrm{~K}$ along the vertical axis, as well as over time.

$\mathrm{C}_{2}$ temperatures at the probe center ranged between $T_{\text {rot }}=5000 \mathrm{~K}$ and $T_{\text {vib }}=5000 \mathrm{~K}$ at the onset of ablation, $1 \mathrm{~s}$ after first exposing the probe to the plasma, and $T_{\text {rot }}=5000 \mathrm{~K}$ and $T_{\text {vib }}=5500 \mathrm{~K}$ after $3 \mathrm{~s}$ of exposure to the plasma. $\mathrm{C}_{2}$ temperatures increased slightly along the vertical (probe) axis to $T_{\text {rot }}=5500 \mathrm{~K}$ and $T_{\text {vib }}=6000 \mathrm{~K}$ at a distance of $32.4 \mathrm{~mm}$ to the probe center. This increase of temperatures along the probe surface was also observed after $2 \mathrm{~s}$ and $3 \mathrm{~s}$, respectively, of exposure to the plasma; see Figure 5.

During $3 \mathrm{~s}$ the density quotient of the simulated molecules was adapted from approximately $\mathrm{N}_{2} / \mathrm{N}_{2}{ }^{+} / \mathrm{C}_{2}(1 \mathrm{~s})=$ $3000 / 70 / 1$ to $\mathrm{N}_{2} / \mathrm{N}_{2}{ }^{+} / \mathrm{C}_{2}(3 \mathrm{~s})=3000 / 70 / 0.4$.

5.2. $3 \mathrm{~mm}$ Axial Distance to Probe Surface. At an axial distance of $3 \mathrm{~mm}$ to the probe surface, at the average heat flux of $1.4 \mathrm{MW} / \mathrm{m}^{2}$, the investigation of $\mathrm{N}_{2}{ }^{+}$during ablation also yielded constant temperatures of $T_{\text {rot }}=9000 \mathrm{~K}$ and $T_{\text {vib }}=10000 \mathrm{~K}$ perpendicular to the plasma jet axis along the probe surface. These temperatures were constant for all radial distances to the probe center investigated, as well as constant in time.

At a density quotient of $\mathrm{N}_{2} / \mathrm{N}_{2}{ }^{+} / \mathrm{C}_{2}=5500 / 70 / 1$, rotational and vibrational temperatures of $\mathrm{C}_{2}$ increased along the vertical distance to the probe center from $T_{\text {rot }}=5000 \mathrm{~K}$ and $T_{\text {vib }}=6000 \mathrm{~K}$ at the probe center to $T_{\text {rot }}=5500 \mathrm{~K}$ and $T_{\mathrm{vib}}=$ $6500 \mathrm{~K}$ at $32.4 \mathrm{~mm}$ distance to the probe center; see Figure 6.

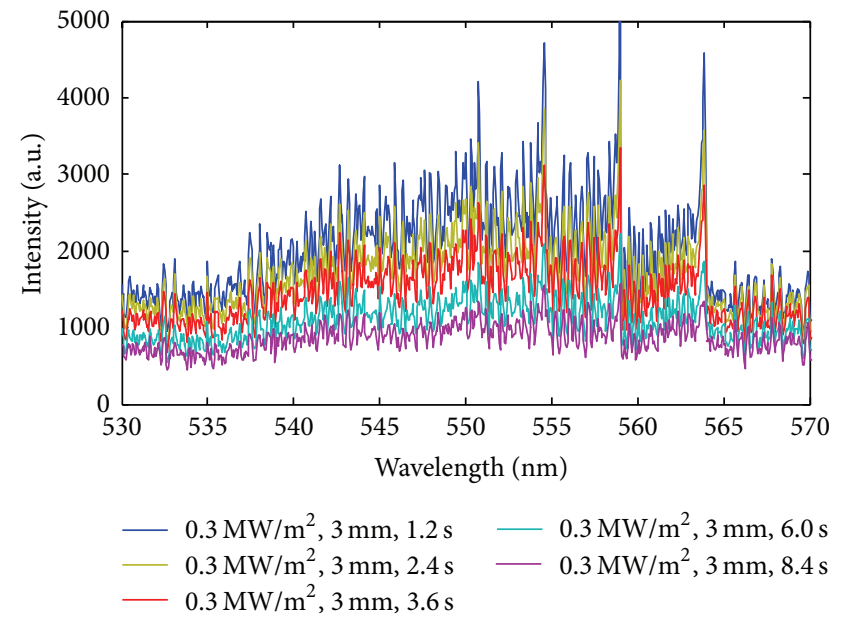

FIgURE 6: Temporal and spatial (vertical) distribution of $\mathrm{C}_{2}$ spectral radiation at $1.4 \mathrm{MW} / \mathrm{m}^{2}$ at $5 \pm 1 \mathrm{~mm}$ axial distance to the probe surface.

At $3 \mathrm{~mm}$ axial distance to the probe surface $\mathrm{C}_{2}$ also showed a transient temporal behavior, temperatures increasing slightly with time towards $T_{\text {rot }}=7000 \mathrm{~K}$ and $T_{\text {vib }}=$ $7000 \mathrm{~K}$ (at $32.4 \mathrm{~mm}$ to the probe center and $\mathrm{N}_{2} / \mathrm{N}_{2}{ }^{+} / \mathrm{C}_{2}=$ $5500 / 70 / 1)$, while particle density quotients decreased to $\mathrm{N}_{2} / \mathrm{N}_{2}{ }^{+} / \mathrm{C}_{2}=8500 / 90 / 0.9$.

\section{Emission Spectroscopic Results for $0.3 \mathrm{MW} / \mathrm{m}^{2}$}

For plasma condition $\mathrm{C}_{2}$, emission spectra of $\mathrm{C}_{2}$ were taken using a $600 \mathrm{~L} / \mathrm{mm}$ grid at a wavelength range of $525 \mathrm{~nm}-$ $575 \mathrm{~nm}$ at an axial distance of $5 \pm 1 \mathrm{~mm}$ to the probe surface. 
TABLE 4: Density quotients $\mathrm{N}_{2} / \mathrm{N}_{2}{ }^{+} / \mathrm{C}_{2}$ for PARADE simulations of $\mathrm{C}_{2}$ at $0.3 \mathrm{MW} / \mathrm{m}^{2}$ at $3 \mathrm{~mm}$ axial distance to probe surface.

\begin{tabular}{lcc}
\hline Density I & $4000 / 90 / 2$ & $1.2 \mathrm{~s}-5.9 \mathrm{~s}$ \\
Density II & $4000 / 90 / 1$ & $4.7 \mathrm{~s}-7.1 \mathrm{~s}$ \\
Density III & $4000 / 90 / 0.8$ & $7.1 \mathrm{~s}-9.5 \mathrm{~s}$ \\
\hline
\end{tabular}

TABLE 5: Rotational and vibrational temperatures obtained using PARADE for $\mathrm{C}_{2}$ at $0.3 \mathrm{MW} / \mathrm{m}^{2}$ at $3 \mathrm{~mm}$ and $5 \mathrm{~mm}$ axial distance to probe surface.

\begin{tabular}{lcc}
\hline $\begin{array}{l}\text { Distance to probe } \\
\text { surface }\end{array}$ & $\begin{array}{c}\mathrm{C}_{2} \text { rotational } \\
\text { temperatures/K }\end{array}$ & $\begin{array}{c}\mathrm{C}_{2} \text { vibrational } \\
\text { temperatures/K }\end{array}$ \\
\hline $3 \mathrm{~mm}$ & $4500-7000$ & 5500 \\
$5 \mathrm{~mm}$ & 5000 & 6000 \\
\hline
\end{tabular}

A second test has been performed using the same spectrometer grid at the same wavelength range at a distance of $3 \pm 1 \mathrm{~mm}$ to the probe surface.

6.1. $5 \mathrm{~mm}$ Axial Distance to Probe Surface. At an average heat flux of $0.3 \mathrm{MW} / \mathrm{m}^{2}$ at $5 \mathrm{~mm}$ axial distance to the probe surface the absolute emission intensity of $\mathrm{C}_{2}$ was very weak and only spectra measured during the first $2 \mathrm{~s}$ of the experiment could reasonably be compared to simulated spectra.

Here, for both density quotients used $\left(\mathrm{N}_{2} / \mathrm{N}_{2}{ }^{+} / \mathrm{C}_{2}=\right.$ $3000 / 90 / 0.5,4000 / 90 / 0.9$, and 5000/90/0.5), at all radial distances to the probe center investigated $(0 \mathrm{~mm}$ and $10.8 \mathrm{~mm})$, both $\mathrm{N}_{2}{ }^{+}$and $\mathrm{C}_{2}$ yielded constant temperatures for both time frames (after $1 \mathrm{~s}$ and $2 \mathrm{~s}$ of exposure to the plasma). For $\mathrm{N}_{2}{ }^{+}$ a rotational and vibration temperatures of $T_{\text {rot }}=8000 \mathrm{~K}$ and $T_{\text {vib }}=9000 \mathrm{~K}$ and for $C_{2}$ of $T_{\text {rot }}=5000 \mathrm{~K}$ and $T_{\text {vib }}=6000 \mathrm{~K}$ were obtained.

6.2. $3 \mathrm{~mm}$ Axial Distance to Probe Surface. At $3 \mathrm{~mm}$ distance to the probe surface at an average heat flux of $0.3 \mathrm{MW} / \mathrm{m}^{2}$ to the probe, $C_{2}$ emission has been observed for more than $9 \mathrm{~s}$, the longest time span of all four experiments.

For the numerical simulations three different densities were used; see Table 4, where the temperature of $\mathrm{N}_{2}$ was again kept at a constant $T_{\text {rot }, \mathrm{N}_{2}}=T_{\mathrm{vib}, \mathrm{N}_{2}}=5000 \mathrm{~K}$, and $\mathrm{N}_{2}{ }^{+}$yielded temperatures of $T_{\text {rot }}=8000 \mathrm{~K}$ and $T_{\text {vib }}=9000 \mathrm{~K}$ for all vertical distances and times investigated.

For all densities, times ( $1 \mathrm{~s}$ to $8.3 \mathrm{~s}$ ) and vertical distances ( $0 \mathrm{~mm}$ and $10.8 \mathrm{~mm}$ to the probe center) were investigated; $\mathrm{C}_{2}$ yielded a vibrational temperature of $6000 \mathrm{~K}$, except for the last spectrum investigated $9.5 \mathrm{~s}$ into ablation, where a vibration temperature of $5500 \mathrm{~K}$ has been obtained; see Table 5 . The respective rotational temperatures are $5000 \mathrm{~K}$ and 4500 $7000 \mathrm{~K}$. Rotational temperatures at $10.8 \mathrm{~mm}$ vertical distance are generally slightly higher than at the probe center at all density quotients investigated, see also Figures 7 and 8.

To ascertain the species identified Table 6 highlights the predominant molecular species, their respective transitions, and band head positions.

6.3. Discussion. In the present study, $\mathrm{C}_{2}$ emission exhibits a transient behavior with time. Several explanations are
TABLE 6: Electronic and vibrational transitions and corresponding band head wavelengths of the predominant molecular species.

\begin{tabular}{|c|c|c|c|}
\hline Species & Electronic transition & $\begin{array}{l}\text { Vibrational } \\
\text { transition }\end{array}$ & $\begin{array}{c}\text { Wavelength/ } \\
\mathrm{nm}\end{array}$ \\
\hline $\mathrm{N}_{2}^{+}$ & $\mathrm{B}^{2} \Sigma_{\mathrm{u}} \rightarrow \mathrm{X}^{2} \Sigma_{\mathrm{g}}$ & $\begin{array}{l}1,1 \\
0,0\end{array}$ & $\begin{array}{l}388.4 \\
391.4\end{array}$ \\
\hline $\mathrm{N}_{2}$ & $\mathrm{C}^{3} \Pi_{\mathrm{u}} \rightarrow \mathrm{B}_{3} \Pi_{\mathrm{g}}$ & $\begin{array}{l}3,6 \\
2,5 \\
1,4 \\
\end{array}$ & $\begin{array}{l}389.5 \\
394.3 \\
399.8 \\
\end{array}$ \\
\hline $\mathrm{C}_{2}$ Swan & $d^{3} \Pi_{g} \rightarrow a^{3} \Pi_{u}$ & $\begin{array}{l}4,5 \\
3,4 \\
2,3 \\
1,2 \\
0,1 \\
\end{array}$ & $\begin{array}{l}547.0 \\
550.2 \\
554.1 \\
558.5 \\
563.5 \\
\end{array}$ \\
\hline CN Violet & $\mathrm{B}^{2} \Sigma \rightarrow \mathrm{X}^{2} \Sigma$ & $\begin{array}{l}0,0 \\
1,1 \\
2,2 \\
3,3 \\
4,4 \\
3,2 \\
2,1 \\
1,0\end{array}$ & $\begin{array}{c}388.3 \\
387.1 \\
386.2 \\
385.5 \\
385.1 \\
358.4 \\
358.6 \\
359.0\end{array}$ \\
\hline
\end{tabular}

feasible for this phenomenon: Pyrolysis, surface/gas phase chemistry, and spallation. A numerical rebuild by Fluid Gravity Engineering [11] indicates that the temporal, transient behaviour of $\mathrm{C}_{2}$ emission may be due to spallation along the samples' surface.

Pyrolysis is ruled out, as in the rebuild; the pyrolysis rate increases with time, and $\mathrm{C}_{2}$ is not a common species as pyrolysis gas.

Considering gas phase/surface chemistry, surface temperatures are too low for $\mathrm{C}_{2}$ to be produced by sublimation and $\mathrm{C}_{2}$ is not a common decomposition product of pyrolysis gases.

Thus, as a hypothesis, spallation is likely to be the cause for $\mathrm{C}_{2}$ transient behaviour. Here, small carbon particles are assumedly ejected into the flow due to the pressure built up of pyrolysis gases in the initial stages of testing. These particles are then transported and heated in the flow, which has been characterized by emission spectroscopy and is therefore known to have temperatures higher than approximately $5000 \mathrm{~K}$. Due to these high temperatures, $C_{2}$ may therefore be produced by sublimation from the spallated particles. As the test proceeds, fissures are formed allowing pyrolysis gases to escape and hence decreasing the rate at which particles are ejected into the flow.

\section{Conclusion}

For a nitrogen/methane gas mixture all in all four ablative probes, consisting of the European ablative material AQ60, have been investigated at two different heat flux regimes $\left(1.4 \mathrm{MW} / \mathrm{m}^{2}\right.$ and $\left.0.3 \mathrm{MW} / \mathrm{m}^{2}\right)$ at two different axial distances to the probe surface ( $5 \mathrm{~mm}$ and $3 \mathrm{~mm}$ ) each. Emission spectra of $\mathrm{C}_{2}$ were taken during these tests, yielding temporal and spatial information on rotational and vibration temperature distributions. 


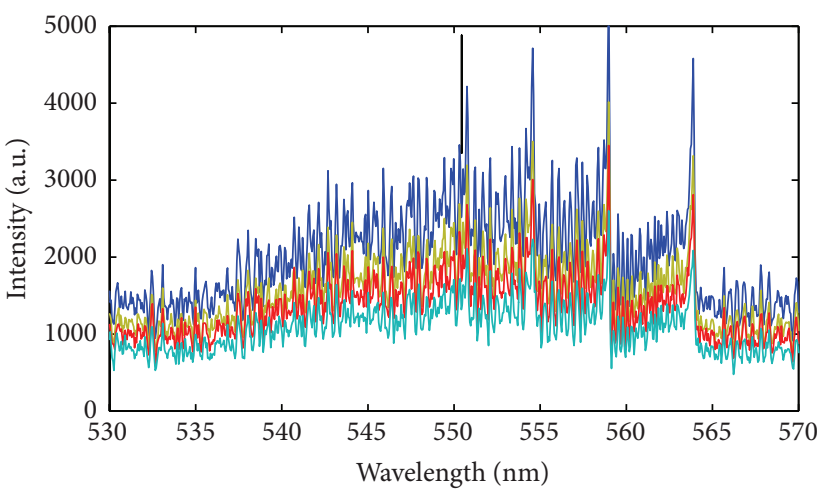

$0.3 \mathrm{MW} / \mathrm{m}^{2}, 3 \mathrm{~mm}, 0 \mathrm{~mm}$
$-0.3 \mathrm{MW} / \mathrm{m}^{2}, 3 \mathrm{~mm}, 8 \mathrm{~mm} \quad 0.3 \mathrm{MW} / \mathrm{m}^{2}, 3 \mathrm{~mm}, 10 \mathrm{~mm}$
$-0.3 \mathrm{MW} / \mathrm{m}^{2}, 3 \mathrm{~mm}, 12 \mathrm{~mm}$

(a)

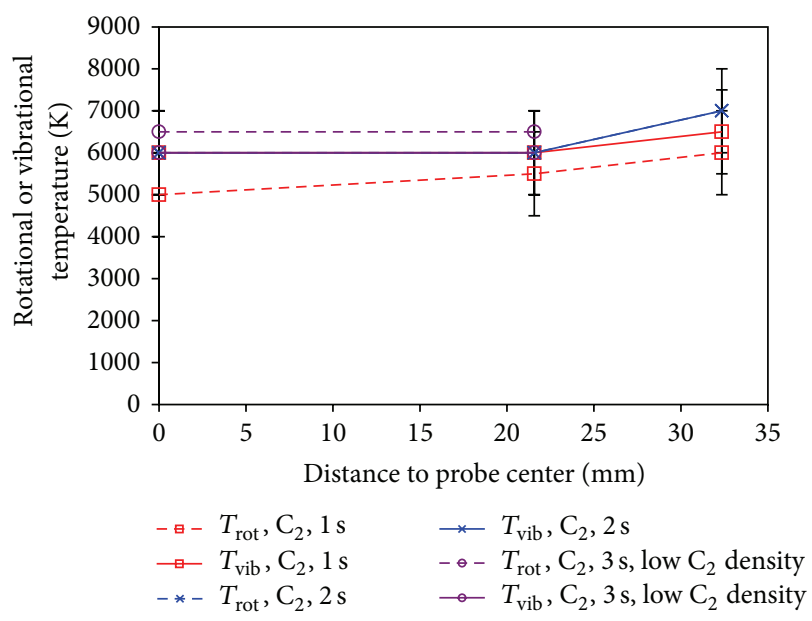

(b)

Figure 7: (a) Spatial evolution of measured spectra at $1.4 \mathrm{MW} / \mathrm{m}^{2} 3 \mathrm{~mm}$ in front of the probe surface; (b) temporal and spatial (vertical) distribution of $C_{2}$ rotational and vibration temperatures at $1.4 \mathrm{MW} / \mathrm{m}^{2}$ at $3 \pm 1 \mathrm{~mm}$ axial distance to the probe surface.

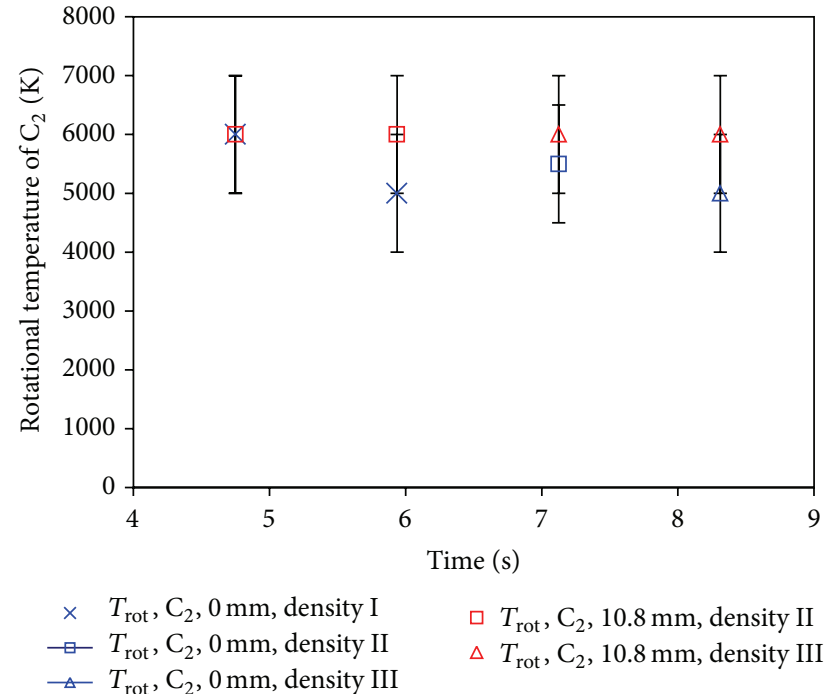

FIgURE 8: Temporal and spatial (vertical) distribution of $\mathrm{C}_{2}$ rotational simulated temperatures at $0.3 \mathrm{MW} / \mathrm{m}^{2}$ at $3 \mathrm{~mm}$ axial distance to the probe surface $5 \mathrm{~s}$ to $9 \mathrm{~s}$ into ablation at different density quotients $\mathrm{N}_{2} / \mathrm{N}_{2}^{+} / \mathrm{C}_{2}$.

After first exposure of the probe to the plasma, rotational temperatures of $\mathrm{C}_{2}$ showed an increase for approximately $5 \mathrm{~s}$, see Figure 9, and are then stable at the vertical distance of $10.8 \mathrm{~mm}$, whereas at the probe center, rotational temperatures decreased slightly after $5 \mathrm{~s}$.

For both investigated heat fluxes, the temperatures of $\mathrm{C}_{2}$ showed a spatial distribution in the vertical direction along the probe surface. Mostly, temperatures increased slightly with distance to the center point, which may be due to the particles being heated by the flow.

Furthermore, $C_{2}$ emission in the observed band showed a transient behavior, intensity decreasing with time, with

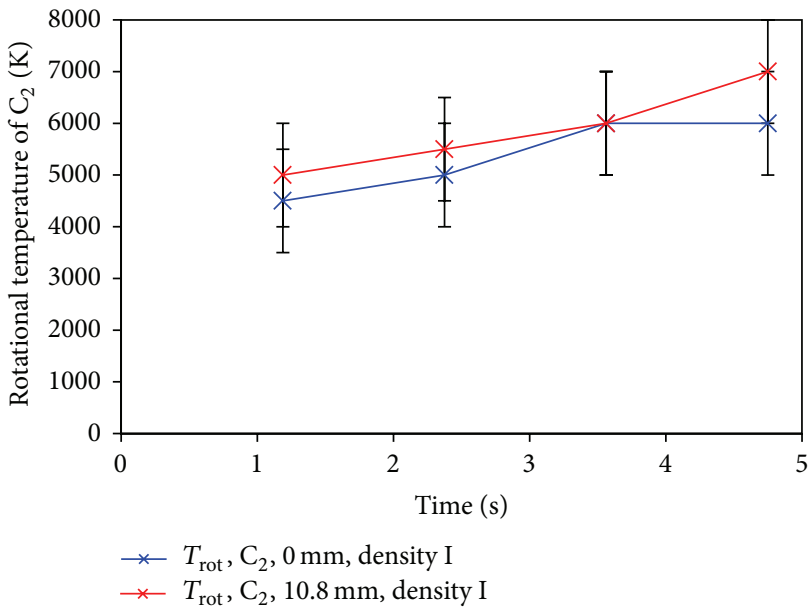

Figure 9: Temporal and spatial (vertical) distribution of $\mathrm{C}_{2}$ simulated rotational temperatures at $0.3 \mathrm{MW} / \mathrm{m}^{2}$ at $3 \mathrm{~mm}$ axial distance to the probe surface $1 \mathrm{~s}$ to $5 \mathrm{~s}$ into ablation.

no visible emission observed after a maximum of $9 \mathrm{~s}$ $\left(0.3 \mathrm{MW} / \mathrm{m}^{2}, 3 \mathrm{~mm}\right.$ vertical distance to probe center). In a very short bullet type summary the following can be derived.

(i) Ablative heat shield materials are characterized in $\mathrm{N}_{2} / \mathrm{CH}_{4}$ plasma as missions to Titan are planned.

(ii) Plasma wind tunnel tests were performed at different heat flux levels, $1.4 \mathrm{MW} / \mathrm{m}^{2}$ and $0.3 \mathrm{MW} / \mathrm{m}^{2}$.

(iii) Emission spectroscopy analysis for free-stream and boundary layer $\left(\mathrm{N}_{2}, \mathrm{~N}_{2}{ }^{+}\right.$and $\left.\mathrm{C}_{2}\right)$ is performed.

(iv) $\mathrm{C}_{2}$ emission behaves transient and numerical rebuild implies spallated particles' sublimation.

(v) As time proceeds, formed fissures promote pyrolysis gas escape. Particles' ejection is decreased. 


\section{Nomenclature}

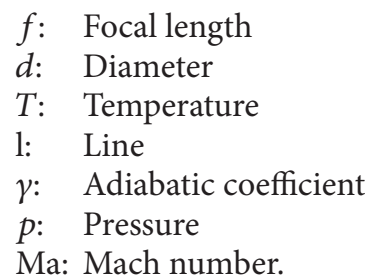

Subscripts

rot: Rotational

vib: Vibration

tot: Total

amb: Ambient.

\section{Conflict of Interests}

There is no conflict of interests.

\section{Acknowledgments}

The authors would like to thank Nelli Eswein, Andreas Steinbeck, and Hannes Fulge for their support during plasma wind tunnel tests. The authors would also very much like to thank ESA for their support within the Aerothermochemistry project, especially for the procurement of the test specimen. Furthermore, The authors want to thank Fluid Gravity Engineering Ltd. for providing numerical simulations within the Aerothermochemistry project, giving a possible explanation for $\mathrm{C}_{2}$ temporal behaviour. This work was supported by the German Research Foundation (DFG) within the funding programme Open Access Publishing.

\section{References}

[1] W. Röck and M. Auweter-Kurtz, "Experimental investigation of huygens entry into the titan atmosphere within a plasma wind tunnel," in Proceedings of the 30th AIAA Thermophysics Conference, San Diego, Calif, USA, June 1995.

[2] W. Röck, M. Auweter-Kurtz, P. Dabalà, H. Früholz, H. Habiger, and S. Laure, "Experimental simulation of the entry of huygens into the titan atmosphere for the thermal protection qualification," in Proceedings of the 44th Congress of the International Astronautical Federation, Graz, Austria, October 1993.

[3] G. Herdrich, M. Fertig, and S. Löhle, "Experimental simulation of high enthalpy planetary entries," The Open Plasma Physics Journal, vol. 2, no. 15, pp. 150-164, 2009.

[4] G. Herdrich, S. Löhle, M. Auweter-Kurtz, P. Endlich, M. Fertig, and S. Pidan, "IRS ground-testing facilities: thermal protection system development, code validation and flight experiment development," in Proceedings of the 24th AIAA Aerodynamic Measurement Technology and ground Testing Conference, Paper AIAA 2004-2596, pp. 2004-2596, Portland, Ore, USA, JuneJuly 2004.

[5] G. Herdrich and D. Petkow, "High-enthalpy, water-cooled and thin-walled ICP sources characterization and MHD optimization," Journal of Plasma Physics, vol. 74, no. 3, pp. 391-429, 2008.
[6] J. G. Marvin and R. B. Pope, "Laminar convective heating and ablation in the mars atmosphere," AIAA Journal, vol. 5, no. 2, pp. 240-248, 1967.

[7] J. C. Boisen and H. A. Curtiss, "An experimental investigation of blunt body stagnation point velocity gradient," ARS Journal, vol. 29, pp. 130-135, 1959.

[8] A. J. Smith, A. Wood, J. Dubois, M. Fertig, and B. Pfeiffer, "Plasma Radiation Database PARADE V2. 2," Tech. Rep. TR28/96 3, Fluid Gravity Engineering, 2006.

[9] H. Liebhart, R. Wernitz, G. Herdrich et al., "Advances for radiation modeling for earth re-entry in parade: application to the STARDUST atmospheric entry," in Proceedings of the 43rd AIAA Thermophysics Conference (AIAA'12), pp. 25-28, New Orleans, La, USA, June 2012.

[10] H. Liebhart, U. Bauder, G. Herdrich, S. Fasoulas, and H. P. Röser, "Numerical modeling of radiative and convective heat flux for entry flights in $\mathrm{CO}_{2}$ containing atmospheres," in Proceedings of the 43rd AIAA Thermophysics Conference, AIAA-2012-3195, pp. 25-28, New Orleans, La, USA, June.

[11] J. Beck, "Validation of aerothermal chemistry models for reentry applications: executive summary," ESA Report and Final Presentation TTS052-11, 2011. 

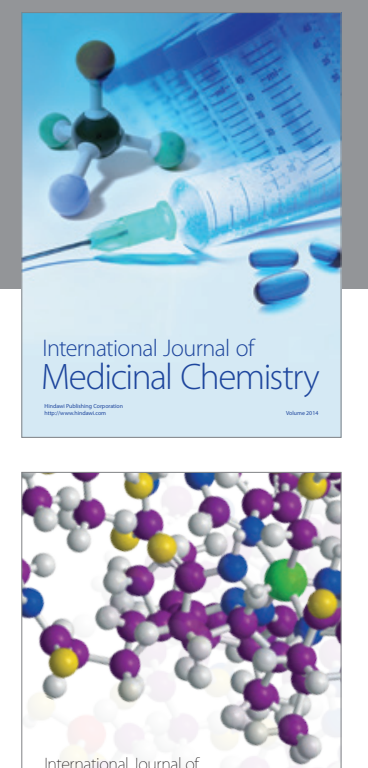

\section{Carbohydrate} Chemistry

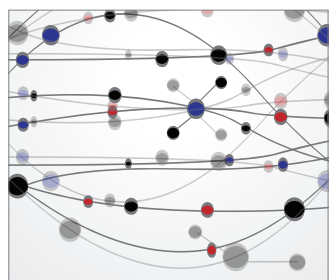

The Scientific World Journal
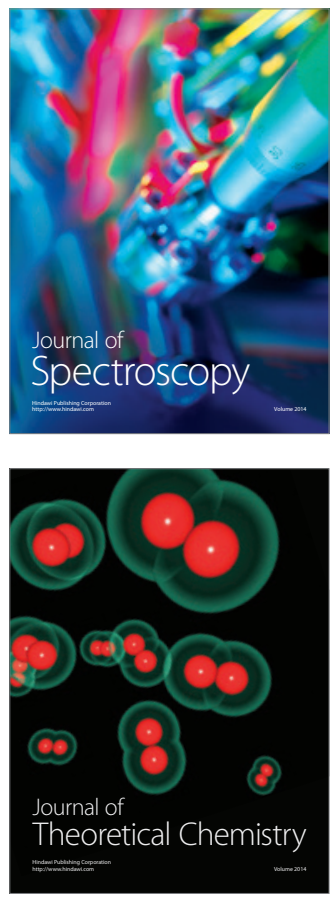
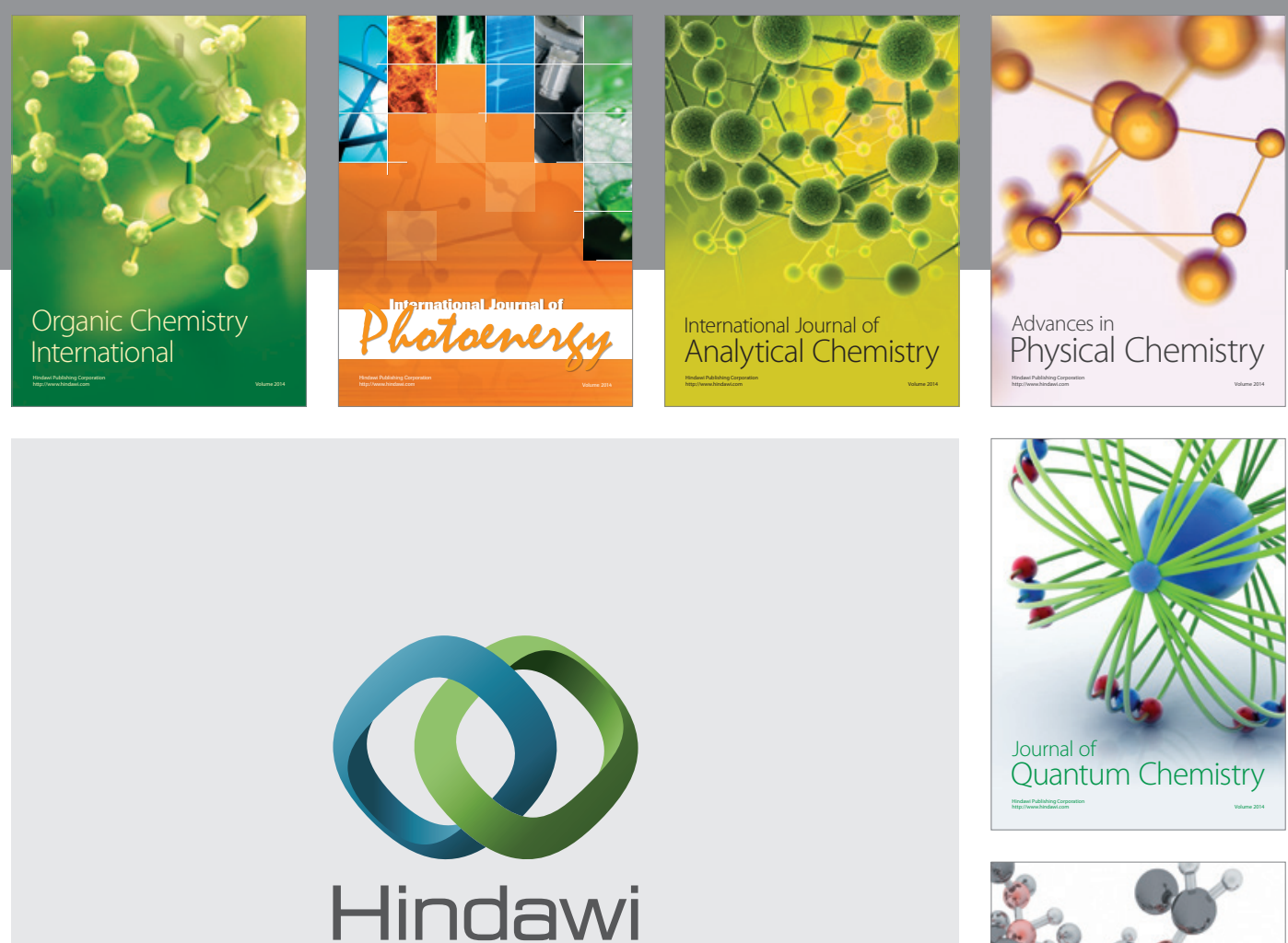

Submit your manuscripts at

http://www.hindawi.com

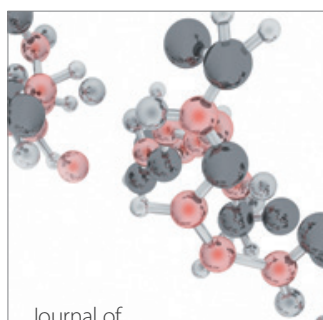

Analytical Methods

in Chemistry

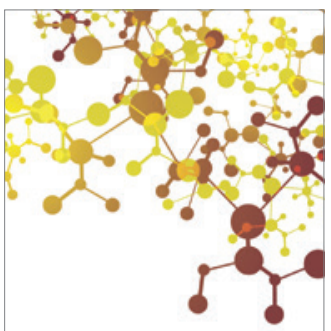

Journal of

Applied Chemistry

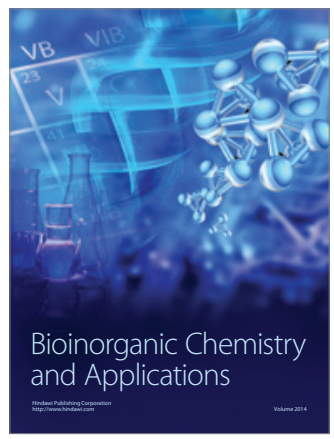

Inorganic Chemistry
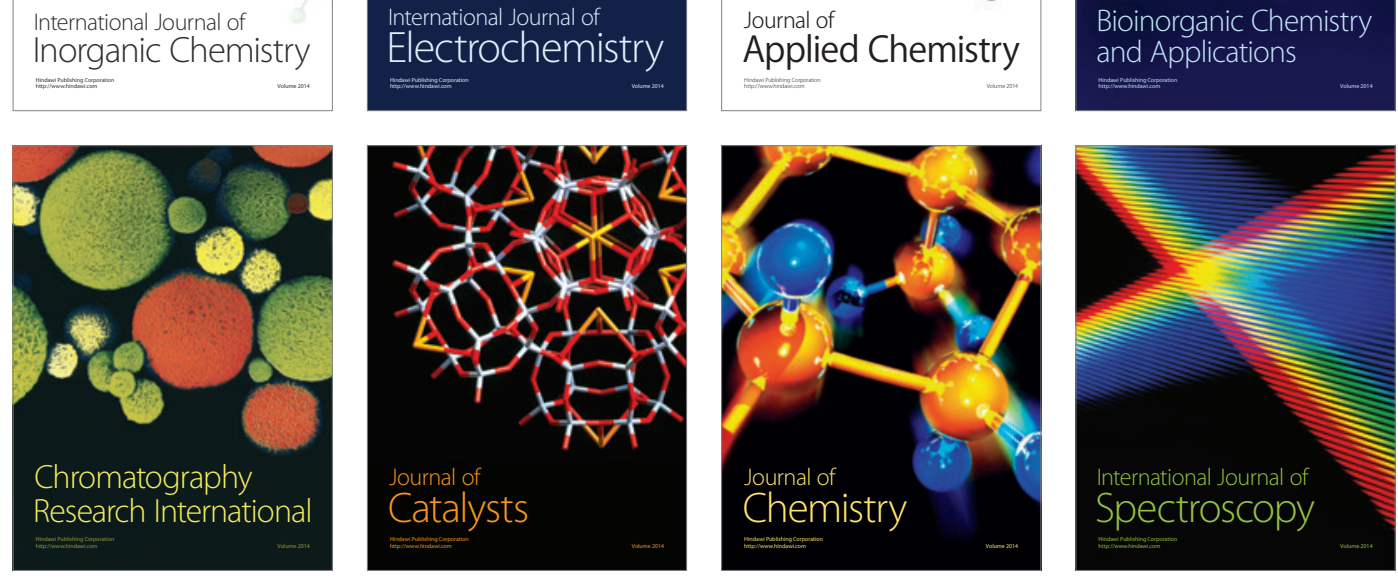